\title{
Awareness on Hazard Analysis and Critical Control Points (HACCP) Principles in TVET and University Hospitality Schools in Kenya
}

\author{
Dr. Monica A. Wandolo, \\ School of Hospitality and Tourism Management of Kenyatta University, Kenya.
}

\begin{abstract}
The purpose of this study was to assess the level of awareness on Hazard Analysis and Critical Control Points (HACCP) principles in TIVET and University hospital schools in Kenya. A total of 671 respondents participated in the study (Comprising 249 from universities, 250 from Institutes of Technology, 64 from Polytechnics and 128 from Technical Institutions). Primary data sources included using structured questionnaires, taking photographs, oral interviews, observation check list and focus group discussions. Secondary sources, on the other hand, involved retrieving information from desk research where journals, books and other relevant literature were obtained. Both descriptive and inferential statistics were used to analyze the quantitative data while content analysis was used to analyze the qualitative data. The analyzed data were presented in terms of graphs and tables. The study found that $83 \%$ of the respondents interviewed were aware of the HACCP principles while $17 \%$ were not aware. The study revealed that $(45 \%)$ respondents from Universities were aware of food safety and hygienic practices compared to respondents from TVET colleges at (38\%). In testing the independence of institution category on awareness, the test yielded a $p$-value $=0.001$, which was less than 0.05 . Since the $p$-value was less than the level of significance, the null hypothesis of independence was rejected. This decision implied that there was a significant relationship between institution category and code of practice on awareness. The study concluded that even though the majority of the respondents indicated that they were aware of HACCP principles and food safety, they did not practice what they knew. It was recommended that there is need to create more awareness on HACCP principles and for food safety by holding workshops, seminars and sensitization programme to the stakeholders of hospitality industry
\end{abstract}

Key Words: Awareness, Hazard Analysis and Critical Control Point (HACCP) principles, TVET, University hospitals schools

\section{Introduction}

According to a report by World Health Organization (2003), the magnitude of Food-Borne Diseases (FBDs) caused by contaminated food and water significantly contributed to a myriad of health problems. FBDs were said to be on the increase despite adoption of vast measures to curb food-related illnesses. The Centre for Disease Control and Prevention (CDC, 2005) attributed this upward trend to increased multiplication rate of disease-causing microorganisms and exposure to high levels of toxins from industrial effluents. CDC (2005) further added that poor hygiene practices, inadequate cooking, improper holding temperatures, use of contaminated equipment and poor personal hygiene contributed significantly to the spread of FBDs. Though symptoms of FBDs varied from one individual to another or from place to place, common symptoms ranged from mild gastroenteritis to life-threatening neurologic, hepatic, and renal syndromes (Hughes, 2000).

Further reports by CDC (2005) indicated that more than 250 different food-borne diseases have been identified and most of the illnesses are caused by microbial contaminants. Some of the most common disease-causing microbes included Escherichia Coli 0157:H7, Salmonella, Campylobacter and Staphylococcus among others (CDC, 2004). Among these groups of microorganisms, some were capable of mutating and re-emerging as new organisms. This feature, frequently observed in Salmonella enteritidis and Escherichia-coli 0157:H7, interfered with the process of reducing FBDs. In the US, for example, a nation- 
wide survey conducted between 1998 and 1999 by the CDC found that microbiological contamination was the number one cause of FBDs followed closely by chemical contamination. Food-related infections were said to constitute a critical health problem in both developed and developing countries (Dugassa, 2007). Further reports indicated that food- borne illness was a major cause of personal stress, preventable death and avoidable economic burden in USA (Mead, Dunne, Graves, Weidman, Patrick, \& Hunter, 1999). It had also been estimated that food-borne diseases causes 76 million illnesses, 325,000 hospitalizations and 5000 deaths each year (Anding, 2001). Additionally, the annual cost of FBDs in terms of pain and suffering, reduced productivity and medical cost is estimated to be between \$10-83billion (Anding, 2001).

Apart from the USA, other developed countries also experienced the burden of FBDs. In Turkey, for instance, a total of 23,010 cases of dysentery were reported in 1997 (Aycikel, 2007). In Emilia-Romagna, a single region in Italy, 1564 episodes of food-borne diseases were reported between 1988 and 2000 (Legnani, 2004). A national survey done by the British government in 2009 revealed that outbreaks of food poisoning had serious financial and social implications (Christopher, 2010). The survey further added that Salmonella alone caused 1939 food-related illnesses (Acheson, 2011). On the same vein, indicated that about one million people suffer from food poisoning every year at an estimated cost of $\$ 1.5$ million annually (Acheson, 2011). Another observation by Rona Ambrose, Minister of Health in Canada (2014), also reported that although Canada boasted of the safest and healthiest food safety systems in the world, the Government was still committed to strengthening food safety by giving tough penalties and cracking down those that did not comply with food safety measures.

In developing countries, particularly in most African countries, a change in socio-economic setting had resulted in multiple food safety challenges (Green, 2003). Green pointed out that between $70 \%$ and $90 \%$ of employees in Africa were in the food trade. These traders were said to significantly influence the prevalence of FBDs in their respective countries. Green (2003) added that availability, distribution and maintenance of adequate supply of portable water and nutritious food were the major challenges to most of these countries. Moreover, inadequate sanitation and physical facilities were said to contribute to lower aesthetic standards, resulting to contaminated food and water (Green, 2003).

According to Dugassa (2007), the burden of food-borne illness in developing countries was significant, and was said to be in a worse condition than developed countries due to inadequate and poorly developed food safety structures and policies. A report by FAO and WHO (2005) indicated that the challenges of food safety in Africa were precipitated by poor food safety systems, lack of systematic surveillance and structural organizations which were viewed as weak and could not protect human health. Besides, there was underdeveloped human resource and insufficient capacity to determine the prevalence and magnitude of the problem. According to Adams (2003), developing countries experienced the challenges of widespread poverty, rapidly growing population and large-scale migration to already overcrowded cities leading to poor sanitary conditions. He further indicated that about 2.6 billion people in developing countries lacked even a simple pit latrine, and about 1.1 billion had no access to portable water. Adams (2003) therefore concluded that food safety was a big challenge due to lack of facilities for hygienic preparation and storage of food.

Kenya, like other countries was not exempted from the burden of FBDs. According to Abegaz (2007), up to $70 \%$ of all diarrhoeal episodes were attributed to ingestion of contaminated food and water. This study viewed training intervention of food handling personnel as a solution not only in Kenya but also in Africa and other developing countries struggling with food safety challenges. It was upon this backdrop that this study aimed at assessing the level of awareness on Hazard Analysis and Critical Control Points (HACCP) practices in TIVET and University hospital schools in Kenya

\subsection{Problem Statement}

Food poisoning is on the increase as a result of consumption of unwholesome food. Food handling personnel are assumed to be responsible for most illnesses as a result of poor handling behaviour. Angelilo, Vigiani, Rizzo, and Bianco (2000) argued that although food handling personnel played an important role in producing food for consumption, they were likely to contaminate the food by introducing pathogens in the process of preparation, production, processing, distribution and service. Studies by Akonor and Akonor 
(2013) indicated food safety was a public health problem associated with consumption of food and water, mainly triggered by improper food handling practices. Studies conducted by Mulan and Wong (2006) reported that an estimated 5.4 million Australians got sick annually from eating contaminated food and that up to $20 \%$ of the illnesses were suspected to originate from inappropriate handling behaviour. In fact, the WHO (2007) also recorded that up to $30 \%$ of individuals in developed countries suffered illnesses related to consumption of food and water hence pointing out that food safety was a major global catastrophe (WHO, 2007).

Kenya is not an exception. A number of FBDs triggered by improper food handling practices have affected the Kenyan population over the years. Abegaz (2007) noted that the most prevalent diseases in Kenya in the year 2004 alone were typhoid, which affected 643,151 people, dysentery, which affected 600,660, and gastroenteritis, which affected 722,275 people. Abegaz also added that aflatoxin poisoning affected 323 and brucellosis 198, while 68 persons were victims of cholera. Based on the frequency and location of the diseases, the report further indicated that some of the FBDs were seasonal and subsequently, required urgent intervention. Other reports indicated that E.coli alone caused an estimated 73,480 illnesses, leading to 2,168 hospitalizations and 61 deaths annually (Rangel, Sparling, Crowe, Griffin and Swerdlow, 2005).

Globalisation, rapid urbanisation, increase in population and change of eating habits has led to a significant increase in the growth of the food service outlets in Kenya. Despite the economic benefits of these sectors, they are viewed as potential hazards especially when food is not hygienically prepared. There is therefore a critical need to provide adequate training for food handling personnel, to ensure that FBDs caused by improper food handling practices are eradicated. This study identified that in Kenya, food handling practices are taught, but when it comes to practice, the ballgame changes. Accordingly, Mortlock, Peters \& Griffith, (2009) observed that efficacy of training in terms of changing behaviour and attitudes to food safety was questionable. However, Clayton and Griffith, (2004) observed that only knowledgeable trained and skilled employees followed proper procedures when handling food. In essence, if food handling personnel are trained on proper food handling practices, there is likelihood that FBDs will take a decline trend. It is upon this background that this study sought to assess the level of awareness on Hazard Analysis and Critical Control Points (HACCP) principles in TIVET and University hospital schools in Kenya

\section{Literature Review}

This Section presents the relevant literature on awareness of the Hazard Analysis and Critical Control Point (HACCP) principles.

\subsection{HACCP System}

According to Egan et al. (2007), HACCP, an internationally recognized food safety assurance system that concentrated on prevention strategies on known hazards, was defined as an effective system based on good manufacturing practice. Effective because it was designed to provide the information flow for preventive and corrective actions and could easily be established on the production lines of all kinds of foods (Ergonul, 2003). HACCP became a regulatory tool in food manufacturing industries and larger companies in hospitality and catering sectors in many countries. The Codex Alimentarius Commission advanced the tool through its adoption in the early 1990s.

It was defined as a method for ensuring food safety since the late 1960s and became recognized and widely endorsed in the 1980s and in the 1990s through its adoption by the US Department of Commerce for seafood, United States Department of Agriculture for meat and poultry and United States Food and Drug Administration for other foods, including juices (Adams, 2002). It was based on the foundation that if biological, chemical or physical hazards were identified as specific points within a product's flow through an operation, they could be prevented, eliminated or reduced to safe levels (Adams, 2002). The HACCP plan was based on the seven basic principles which included conducting a hazard analysis, determining critical control points (CCP), establishing critical limits, monitoring the procedures, identifying corrective actions, verifying that a system works and establishing procedures for record keeping and documentation. HACCP system could also be used to control risks and hazards throughout the flow of food, which as seen earlier, entailed food-handling practices from farm to fork. 


\subsection{Standard Operating Procedures}

In all HACCP plans, there were acceptable procedures and practices that food service organizations were expected to follow. These were called Standards Operating Procedures (SOPs) and were meant to ensure that food produced was not only safe but its consistency was maintained according to the set standard. The first principle was to identify and assess the potential hazards in the food served, which was done by looking at the menu and identifying where food hazards were likely to occur. Hazard included contamination by bacteria, viruses or parasites.

The second principle of HACCP application was to determine critical control points, as lack of hazard control at critical points could lead to unacceptable health risk. This procedure helped to identify the points in the process where biological, physical or chemical hazards could be prevented, eliminated or reduced to safe levels. The process entailed reviewing the menu items and the steps in the food flow (purchasing, receiving, storing, preparing, cooking, holding and serving). Critical control points varied from one operation to another, since, as seen, there were many steps in food preparation. The basics however included cooking, cooling, hot /cold holding, maintaining specific procedures, preventing cross contamination and ensuring that food handlers practiced safe food handling. Time and temperature control were said to be critical due to the vegetative, spore and toxic forming bacteria.

The third principle involved establishing critical limits. Paster (2007) defined a critical limit as the specific scientific measurement that clearly indicated what needed to be done at each critical point (Paster, 2007). Critical limits were to be attainable, realistic and needed to be met for each preventive measure. Sensory tools were used in evaluating critical limits. These included the nose for detecting odours, eyes for visual confirmation of quality and hands for touch (Paster 2007). For example, the freshness of fish would be determined by pressing the body of the fish. If it sprung back instantly without creating a dent, that confirmed that it was fresh. The visual appearance of red gills or intact eyes would also imply good quality.

Paster (2007) argued that time and temperature control was the most common critical limit that was used in schools and other operations. The tools needed for time temperature control included a clock with second hand timer and a calibrated cleaned and sanitized thermometer to measure time and temperature. A thermometer was used to measure the minimum internal cooking temperature of potentially hazardous foods. Baked items were to be "cooked until done" or "cooked until juices ran clear" by cooking at an internal temperature of $165^{\circ} \mathrm{C} \mathrm{F}\left(73.9^{\circ} \mathrm{C}\right)$ for 15 seconds.

The fourth principle entailed establishing monitory procedures, which were the foundation for HACCP. The actions involved putting in suitable place time and temperature control systems in the food operation. A correct monitoring procedure ensured that food served was safe. It also provided tracking for the food safety management system throughout the operation. The areas of concern included fault rectification, especially in equipment and/or personnel. Monitoring was done by identifying staff, training them to use equipment designated to measure the critical limits and in the standard operating procedure. Other monitoring tools included documentation and record keeping.

The fifth principle involved identifying corrective action. These were the pre- determined steps to be taken if the critical limits were not met. Corrective actions involved tasks, which included rejecting a product that did not meet the standards in terms of size, quality, quantity, brand or other purchase specification. It also included rejecting a product that did not come from reputable source. The risks included poor quality food, undercooking and cross contamination. Contamination introduced a number of unknown risks to the consumer. It was recommended that cooking food until it reached the correct internal temperature and subsequently reheating it to $165^{\circ} \mathrm{C} \mathrm{F}\left(73.9^{\circ} \mathrm{C}\right)$ and monitoring would alert the worker of the temperature danger zone (TDZ).

Principle six was verification to check or confirm that the plans were working. It ensured that the operation was an effective food safety management system. Validation was a component of verification, which focused on collecting, purchasing, receiving, storing, preparing, cooking, holding (hot), cooling (cold), reheating and serving. 
The last principle, seven, was to establish a procedure for record keeping and documentation. It entailed keeping all the documents created when developing the programme, as well as keeping the records to monitor how activities were performed.

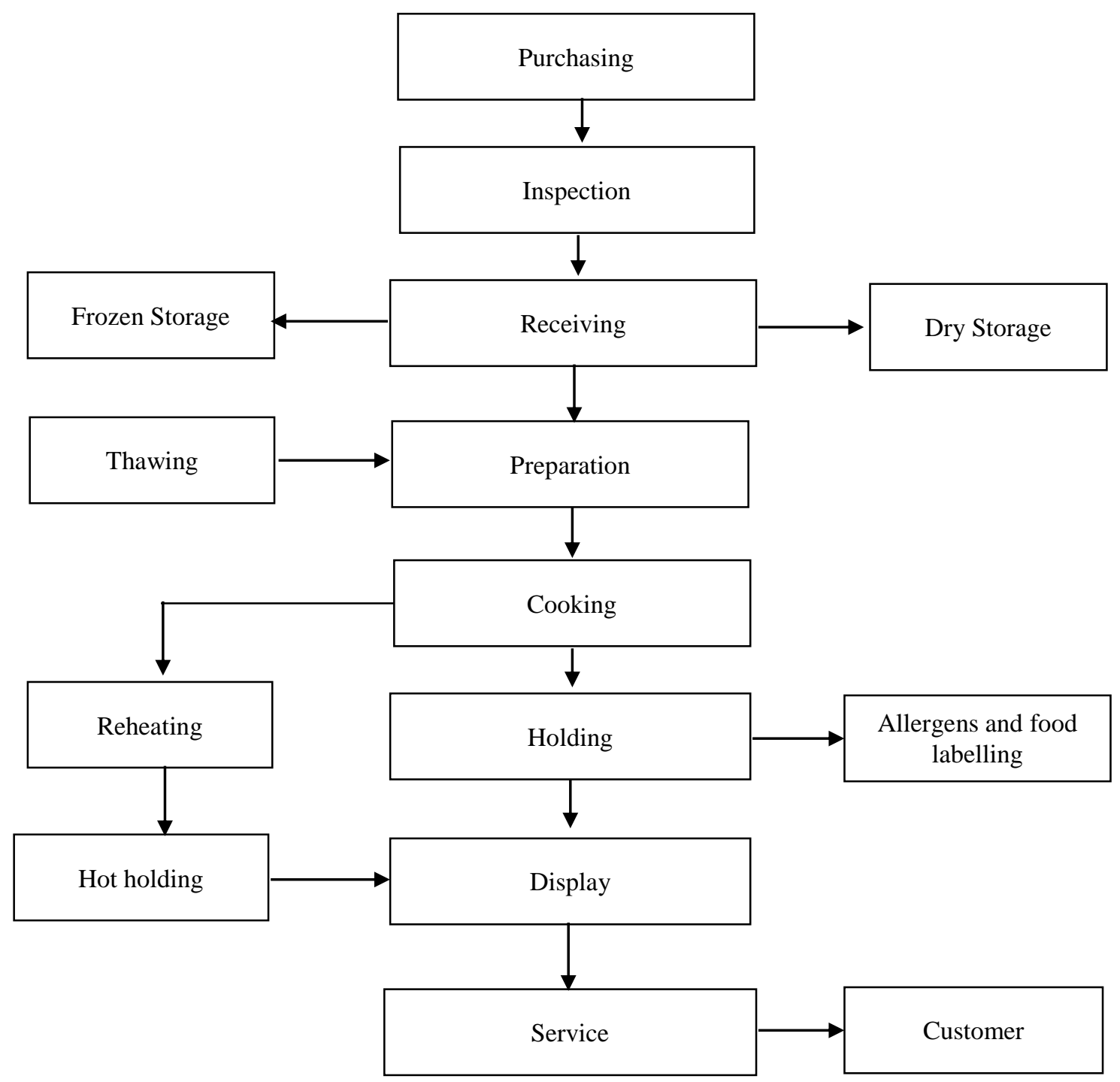

Source: Adopted from Hause and Martel (2011)

Table Error! No text of specified style in document..1:- Summary of a Food Flow Audit

\subsubsection{Purchasing}

This was the first step in the food flow where the ingredients to be used were bought. The key issue in this step was the choice of a supplier. There was need to choose a supplier who could safely deliver safe food (Lewis, 2005). To ensure that selected suppliers got products from safe, approved sources, they were required to possess a well-documented good manufacturing practices (GMP) program. The program prescribed methods, equipment, facilities and controls used to process food according to the Food and Drug Administration (FDA) and Lewis, Michael and Heppell (2005). In addition, a supplier was required to have a good reputation in relation to packaging and/or delivery of food substances (Jung, 2005). Where possible, a food handler needed to inspect a supplier's warehouse to check whether the firm was HACCP compliant and whether his/her members of staff were trained (Lewis et al., 2005).

Farm produce suppliers had to have Good Agricultural Practices (GAP), which included audit measures on water supply and sources, employees' personal hygiene, facility and equipment sanitation, training and documentation inspection, proper labelling and pest control, and good storage and warehouse - practices (Lewis et al., 2005). The critical points in purchasing would be packaging, storage and transport facilities. The controls to be implemented during purchasing included getting an approved supplier, who was able to 
transport goods in refrigerated vehicles where temperatures would be checked in case the supplies were out of date.

\subsubsection{Receipt and Inspection}

Food products delivered to any establishment needed to be carefully checked for damage, potential contamination and proper temperature (Keith and Weenen, 2006). In addition, all foods received had to be checked for proper texture, appearance, smell, and where possible, taste (Keith \& Weenen, 2006). For example, poultry had to be checked to ensure firm texture, freshness and no discolouration. For meaty foods, the substance was to have no odour and the packaging was to be surrounded by crushed self-draining ice. In case of discoloration to purple or green around the neck or dark wing tips, the product was to be rejected. In case of stickiness under the wings and around joints and unpleasant and abnormal odour, the meat needed to be rejected. Other products such as dairy products had to be checked for freshness, abnormal colour, odour, and taste among others to determine product quality. Dry foods were to be inspected for pest infestation and moisture. Baked goods were not to have moulds or show signs of pest damage. Controls at this point would be checked on the rotation of the stock and different food items separated and stored according to minimum required temperature.

\subsubsection{Storage}

Poor storage practices caused food to spoil quickly with potentially serious results (Keith and Weenen, 2006). Improper food storage deteriorated food quality and safety. Food was to be stored in designated areas and rotated to ensure the oldest product was used first (FIFO) (Lewis et al., 2005). Dry storage areas were to be kept at appropriate temperatures and humidity levels. Stores were to be well ventilated to maintain food quality. Food in dry storage was to be stored away from walls and off the floor. Fresh meats, poultry, fish and dairy products were to be stored at $41^{\circ} \mathrm{F}$ or lower, and seafoods stored in their original containers at an airtight temperature of $45^{\circ} \mathrm{F}$. Since microorganisms did not die when frozen, storage facilities were to be controlled, and the temperatures for the wide range of products to be stored noted. A few general rules were to be followed, such as labelling of food, rotation of produce to ensure that the oldest inventory was used first, and checking temperature of food as stored and in storage areas.

\subsubsection{Preparation}

Good personal hygiene was a critical protective measure against food-borne illness. Todd and Farber (2002) observed that food handlers contaminated food and caused customers to fall ill by transferring microorganisms to food they touched. This was likely to happen especially if they had a food-borne illness, showed signs of gastrointestinal illness, had infected lesions through wounds or cuts, or even when they lived with a person who was ill. Control in the production would ensure that food was not kept in the temperature danger zone for more than 30 minutes, good personal hygiene was maintained and both equipment and premises were clean.

CDC (2010) developed a voluntary food safety strategic plan (2010) which was implemented on food safety management based on HACCP, to evaluate and control the risks in food and water. Food safety strategic plan (2010) indicated that rather than responding to food-borne illnesses when they prevailed, prevention would be taken by adapting a proactive approach. This approach involved using a manual that provided a roadmap for writing and voluntarily implementing food safety management. This was to ensure that food served in any establishment was safely managed.

\subsubsection{Application of HACCP Pre-Requisites}

HACCP was not a substitute for the codex general principles of food hygiene. It was the code of safety requirement put in place before beginning the HACCP process. The prerequisite food safety programs included personal hygiene programme, supplier selection and specification, sanitation and pest control programmes, facility design and equipment maintenance programmes on food safety training programs. The first principle in application of HACCP was, therefore, to check on the prerequisite food safety programmes. Some aspects of the principle are discussed below.

\subsubsection{Prerequisite to Food Safety Programmes}


Personal Hygiene: The main objective of personal hygiene was to ensure that those who came directly or indirectly into contact with food were not likely to contaminate it. Paster (2007) asserted that maintaining an appropriate degree of personal cleanliness and behaving in an appropriate manner achieved this. Some of the principles of personal hygiene for food handlers included not handling food or entering food preparation areas if one was suspected to be suffering from diseases or illness likely to be transmitted through food, reporting any illness to management, wearing suitable protective clothing and washing hands before handling foods, both after using the toilet and between handling of raw and cooked food.

On the other hand, a sanitary facility was considered a prerequisite programme to manage crosscontamination and prevent microbial growth (Paster, 2007). Facility designers were expected to consider the flow of the product through the operation from the source to the customer. Among the considerations included the interior materials of walls, floors and ceilings, equipment locations and flow the spacing of shelves off the floor and away from the walls. Also to be considered was the ease of cleaning. Besides, workshops were required to have adequate lighting and ventilation, correct humidity, portable water and water controls on the floor with properly fitted drainages with effective plumbing, well fitted with a back flow prevention device, air gaps and vacuum breakers (Paster, 2007).

Product (ingredients used in production): The raw materials were considered in terms of source, lifespan and storage conditions. Knowledge of their chemical, physical and microbiological composition was equally important (Mitchel, Fraser \& Bearon 2007). The products had to be safe in terms of microbiological, chemical and physical hazards. Preservation methods used on products such as cheese, yoghurt, meat, fish (dried), vegetables and fruit including packed foods and jams were designed to prevent the growth of clostridium botulinum, a deadly pathogen given the dangerous effect of clostridium botulinium toxin.

According to (Mitchel et al., 2007), the factors that controlled the growth and survival of microorganism included time, temperature water activity, acidity, atmosphere and preservatives. There was need to control and monitor the activities of the operations in food service areas and in particular the causes of food contamination and determine the control measures, to be applied at each stage of operation.

Pests Management: According to the European Food and Drug Administration code, Regulation (EC) NO. $852 / 2002$, food premises had to be designed sited and constructed to permit good hygiene practices including protection against, contamination and in particular, pest control. The purpose of these clauses was to control infestations of pests. McLauchlin and Little (2007) noted that pest infestations were caused by inadequate cleaning, poor building maintenance as well as suppliers' deliveries. Common food area pests included rodents (such as rats, mice, squirrels), birds and insects (such as cockroaches, flies, ants and wasps). Pests in food production areas were repugnant, as they caused food spoilage and destroyed fabrics in the building surfaces. In addition, they introduced pathogens to food hence cross contamination through their body parts, fur, eggs and droppings, leading to infection (Blanch, 2003).

Rodents: There were over 400 types of rodents and rats found in East Africa (Jonathan, 2005). Their presence in premises not only posed a risk to food safety but also led to material loss and potential danger to health (Elson, 2006). Two species of rats were commonly encountered at food premises; the brown rat (Rattusnorvegicus) and black rat (Rattusrattus). These rats were omnivorous and had a preference for cereals. Both rat species were xenophobic. They colonized sewer systems and took advantage of defective pipe work and open drainage systems, as well as tunnel systems beneath and around the buildings. Mice (muscular/domestic) were on the other hand smaller and less habitual, and were less consistent in travel routes. Both rats and mice were nocturnal and were rarely seen during the day. A large number of droppings that differed in size and shape identified their presence in the premises. Their fur was greasy and sometimes left smear marks on walls and other surfaces over a period of time (Elson, 2006).

Rodents required food, water and shelter to survive (Bassett, 2004). Prevention of their infestation included proper storage of cereals, starchy vegetables and fatty compounds (including soap) in rodent-proof metal/plastic bines or containers. Refuse of the same type were collected in property covered metal/plastic dustbins. Food stored in sealed containers off the ground and away from walls was safe if the storage area was cleaned regularly, and, in addition, spillages cleaned immediately to prevent build - up of food. Accessibility of water was curtailed by mending dripping taps and having grids on gulley taps.

Good housekeeping was important especially when food preparation equipment and other items such as storage boxes were not used for some time; they provided harbourage for the rodents and were not allowed to remain undisturbed for a few weeks. Anything that afforded cover for the rats and mice was to be 
removed from the buildings. Access routes for rodents such as service pipes entering and leaving the building were to be filled (Elson, 2005). All the drains were to be maintained in good repair, other inlets such as manholes and rotting door edges were to be properly sealed and covered.

Cockroaches: A large number of cockroaches were found in diverse environments worldwide. Cockroaches sought warm moist environments and they readily infested premises. They mostly fed at night and readily infested food with their faeces and by regurgitating the contents of their stomach on to the food. They fed on food, refuse and any food with organic content (Elson, 2005). They lived in and around drains and sewers. Two species of cockroaches commonly found included the German cockroach (Blattagermanica) and the orientate cockroach (Blattaorientalis). Good design construction and maintenance of premises was essential to control and prevent infestation. Besides, routine baiting and the application of a residual insecticide on the walls and floors hindered the progress on their lifecycle. While in food preparation areas, gel and paste baits were to be used to prevent contamination of foodstuff (Elson, 2005).

Flies: Flies spread disease and carried eggs of parasitic morons. They fed on refuse or dung/sewage and then settled on sugar, jam, cheese, meat, bread, milk or any food. In turn, they infected the human food with microorganisms that led to infection. There were several species of flies in and around food premises which included houseflies, bluebottle, blowflies, vinegar flies, fruit flies (Elson, 2005). They readily moved between faeces, refuse and fresh food while feeding and were known to carry pathogen in their bodies. During feeding, flies regurgitated their gut content onto food and defecated randomly. The danger of flyborne contamination of food cannot be underestimated and all steps must be taken to deny flies access to food.

Prevention included covering both raw and cooked food, installing fly screens to windows that were open, and providing ultraviolet insectculators at strategic points in the food production areas. Furthermore, there was need to clean and remove food particles and refuse that accumulated in the worktops and on the floor. Regular spraying of the premise with natural or synthetic pyrethrins also removed other insects such as Pharaoh's ants, wasps, and other beetles, which infected foods. These included larder beetles, flour beetles, flat grain beetles, spider beetles, grain weevils, mites and moulds in food processing premises (Elson, 2005). Control of Pests: Pest infestations were prevented or controlled by fumigation or spraying by an insecticide. Also, good stock rotation was essential in preventing recurring problems. Most of these pests lived on or in food during storage. Food deteriorated in appearance and taste whenever pests contaminated it. Thorough cleaning and maintenance of high hygiene standards went a long way in reducing pest infestations.

\subsubsection{Waste Disposal}

Kitchen waste was unique and was mainly organic which required special care from the on-set pending the final disposal. Catering waste included all waste produced in the process of food preparation and it included used cooking oils, ingredient waste from peelings and trimmings and water waste, among others. Internationally, these types of waste were only disposed of under certain regulations such as By-Product Regulations 2005. According to Robbs (2005), disposal by disintegration and flashing to the drainage system was the most convenient method of waste management. Robbs, further recommended disposal systems fixed under metal sinks for food service out-lets and asserted that an electrically driven macerating unit which broke down the waste food to a fine suspension that would wash away waste through trapped pipes were the best (Robbs , 2005). However, these kinds of fitting were only to be done with permission from the relevant authority, for example, if the waste was destined for use in a biogas plant or animal consumption or was intended for composting with approval (Robbs, 2005). Other reports indicated machines for waste disposal, which were able to reduce bulky refuse to a smaller size, were also available. Moreover, catering waste, which was disposed of through landfill or incineration, had to be handled in such a way that livestock and birds would not access it (Robbs, 2005).

Paper and plastic sacks, on the other hand, were placed inside the bins to prevent attacks from vermin, domestic animals and birds. Waste containers were required to conform to the relevant British Standard specification. Dust-bins were supposed to be of a normal capacity of $90 \mathrm{~L}$ and the lids would fit in closely with an overlapping lid. The bins would be wheeled to ease the movement of waste from the premises.

In developing countries where waste management was and still is a major challenge, the waste was disposed of either in pits dug by institutions or disposed of at strategic places to be collected by county councils in lorries. In significant institutions, properly constructed storage areas for refuse with concrete floor were put 
in place. The refuse storage areas consisted of a concrete platform and included a bund wall to prevent spillage and washing. The wall surfaces had to be smooth, impervious and able to withstand water.

\subsection{Barriers to HACCP Implementation}

Panisello and Quantick (2001) and Codex (2003) reported that during the last three decades, HACCP, an internationally recognized system of managing food safety, had been progressively introduced and applied comprehensively in the food industry. According to CDC (2005), HACCP was considered an important system because it had saved lives. The system was considered as an efficient tool by both the industry and health authorities in the prevention of food-borne diseases (Motarjemi and Kâferstein, 1999).

Despite the positive attributes that came with the introduction and adoption of HACCP, the system faced a lot of challenges in the hospitality training colleges and practical and psychological barriers hampered its full implementation (Codex, 2003). The HACCP system required the management team to provide commitment, strong leadership and adequate resources for the programme to succeed (CDC, 2005). However, the system was compounded by a number of challenges, which included lack of financial resources, lack of time, caterers handling a wide range of different foods on the menu, lack of technical expertise and trained personnel, in addition to other internal and external barriers such as staff turnover. Given the complexities in the operation of the food business, HACCP system was seen as a burden in itself since the industry had challenges in adapting to different operational working patterns in addition to unexpected variations in demand and workload on the menu.

Furthermore, lack of financial resources, technical expertise and small staff base impeded HACCP system implementation, both in small and large food outlets. The HACCP philosophy simply stated that biological, chemical or physical hazards be prevented, removed or reduced to safe levels at certain times in the flow of food (CDC, 2005). Taylor (2008) argued that the classical implementation in hospitality of HACCP was exaggerated and that HACCP understanding by institution was very poor. Besides, the bureaucratic process was confusing the stakeholders in the food industry. Taylor (2008) further observed that confusion existed between prerequisite programmes and HACCP layout and how they should be managed. The confusion was attributed to negative guideline factors and lack of understanding attributed to barriers (Vela and Fernandez, 2003).

Walker, Pritchard and Forsythe (2003), reported that prerequisite activities scored satisfactory with the exception of cleaning and disinfection in UK food businesses. According to this survey, the main barrier to implementing a HACCP- based food safety management system was lack of prerequisite programmes, lack of knowledge, inadequate sources and cost related to HACCP. Problems of implementing HACCP in food businesses were named as inadequate equipment and physical conditions of the facility (Bas, Ersun and Kivanc, 2006). Well- designed premises with modern and reliable equipment were perceived as a way of protecting ingredients and food products, maintaining hygienic conditions, improving cleanliness besides controlling pest infestations.

Time and money were identified as obstacles in implementing HACCP, according to Giampaoli (2002). Giampaoli also found that food service directors positively agreed on the benefits of certification and continuing education related to food safety. Panisello and Quantick (2001) and Ward (2001) observed that managers seemed to find it difficult to make their employees understand the importance of hazard analysis as well as why particular operations had to be monitored and controlled when time and money were inadequate. While examining barriers to HACCP implementation in food businesses, Hwang, Almanza, and Nelson (2001) found that Indiana School foodservice managers identified time to establish a HACCP programme, time to run the programme, and labour costs as being the three biggest obstacles. In addition, lack of funds for training, time to get used to running the HACCP programme, and union problems were also cited as major obstacles.

The researchers identified three types of barriers: resource management, employee motivation and confidence. The study also found that employees were nervous about taking food safety certification examinations and were not comfortable with the change needed for implementation of a programme like HACCP. Sneed and White (2002) identified employee and resource barriers in a national study of school foodservice directors. Lack of employee training was the biggest employee barrier and lack of financial resources to devote to food safety was the biggest resource barrier.A study carried out in Ontario, Canada identified four key areas which included low priority given to enhancement of food safety controls, financial constraints, and the perception that HACCP was of questionable appropriateness (Deeponada \& Spencer, 
2010). The study concluded that HACCP implementation was impeded by barriers related to financial constraints, and that the most important drive to promote implementation of HACCP was customer requirement for HACCP to be implemented in supplier facilities.

Lee (2005) cited lack of teachers' support on students' education and limited availability of equipment and facilities as the biggest challenges in implementing HACCP. The study suggested that more investment on facilities and equipment were needed for food safety improvement and successful implementation of the system. Furthermore, the study also recommended that proper training of employees and improvement of facilities would help the employees monitor the critical control points (Lee, 2005). On the same vein, research carried out in Sankara, Turkey, indicated that HACCP was to be clearly defined, its importance assessed and its implications evaluated (Panisello \& Quantic, 2001). Figure 1 below presents the barriers to proper food safety and hygienic procedures.

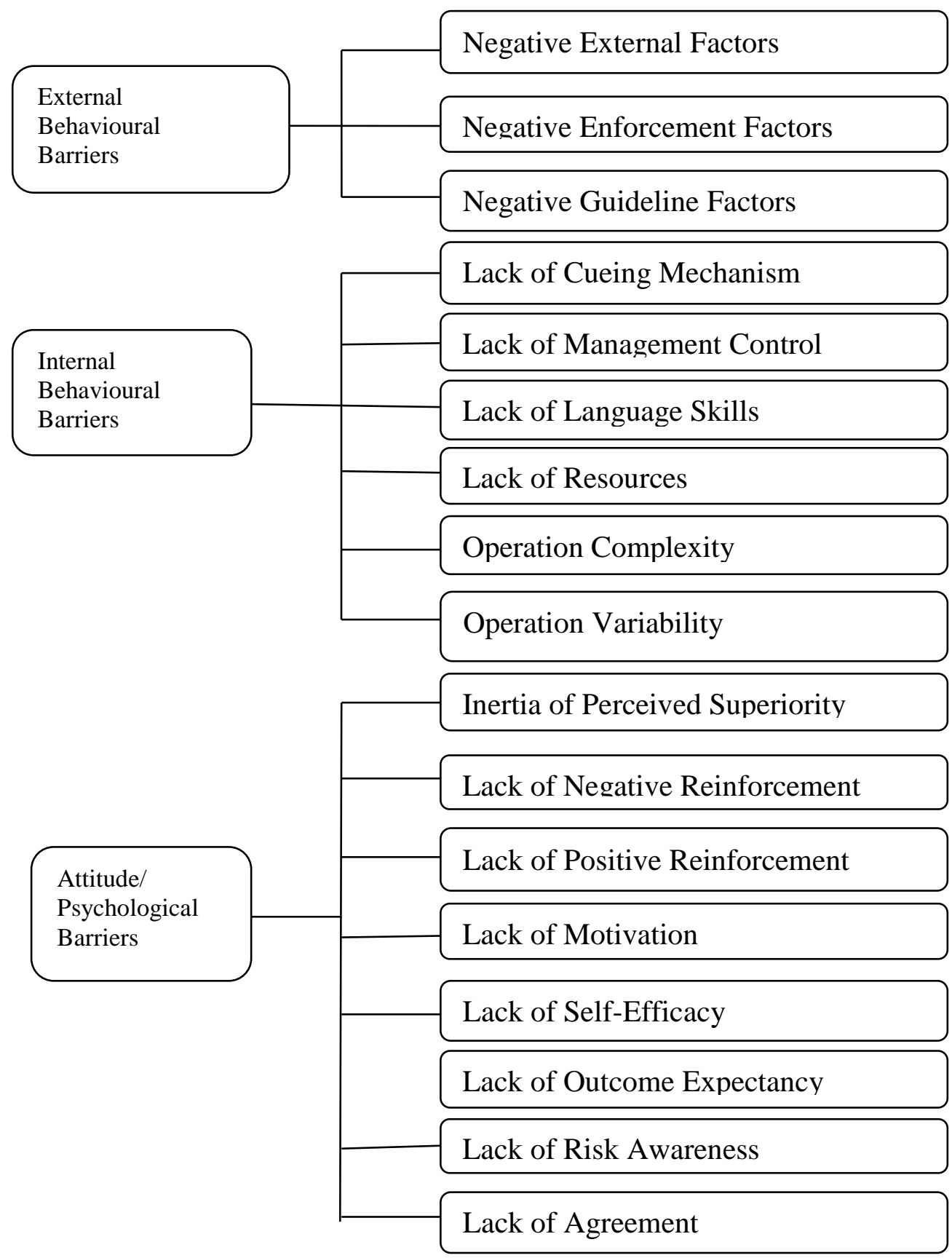

Source: British Food journal (2005)

Figure 1:- Barriers to Proper Food Safety and Hygiene Practices

\section{III: Methodology}

Descriptive cross sectional survey design was used in the study. The design combined both qualitative and quantitative data collection and analysis techniques. Quantitative data was derived from questionnaires 
while qualitative data was generated from interview schedules. The design was therefore appropriate for the study since this study was interested in establishing the facts as they are in relation to food and hygiene practices in training institutions. The study was carried out in TVET institutions offering diploma programs and university hospitality schools offering degree programs in Kenya. The TVET institutions included Polytechnics, Institutes of Science and Technology and Technical Training Institutions (TTIs). There were over 44 TVET institutions and over 10 university hospitality schools in Kenya that offered courses in food and beverage production and service. The inclusion criteria consisted of all third year students in TVET institutions who were almost graduating, and third year students from Universities who had covered three quarters of the course-work. First and Second years were excluded from the study as they had not had enough exposure in food production or food and beverage service. Heads of Departments of these courses were also included, as they represented their various institutions. A total of 671 respondents participated in the study (Comprising 249 from universities, 250 from Institutes of Technology, 64 from Polytechnics and 128 from Technical Institutions).

In the selection of respondents, both probability and purposive sampling techniques were used. Probability sampling technique was used in selection of student-respondents. In this case, each target student-respondent was pre-assigned some chance of being included in the sample. This technique was used since it minimized biases in sample selection. As one method of probability sampling technique, lottery method was used to identify specific sample units. This was done using identical cards where numbers were written and cards drawn at random. Population unit whose identification number corresponded to a drawn card was selected. This procedure was repeated for all the sample units. On the other hand, purposive sampling technique was used in the selection of staff-respondents. This technique was used since it facilitated the provision of focused information, besides being able to save time and money. Both primary and secondary data were used in the study. Primary data sources included using structured questionnaires, taking photographs, oral interviews, direct observation and focus group discussions. Secondary sources, on the other hand, involved retrieving information from desk research where journals, books and other relevant literature were obtained. Questionnaires were used to collect data from students and lecturers while interview schedules were used to collect data from departmental heads. Both descriptive and inferential statistics were used to analyze the quantitative data while content analysis was used to analyze the qualitative data. The analyzed data were presented in terms of graphs and tables.

\section{Findings of The Study}

This section presents the findings of the study on awareness of Hazard Analysis and Critical Control Points (HACCP) principles in TIVET and University hospital schools in Kenya.

\subsection{Level of HACCP Awareness in TVET and University Hospitality Schools}

The purpose of the study was to know the level of awareness of HACCP and food safety pre-requisites as stipulated by Codex Alimentarius regulations on food safety and hygiene. To achieve this, the students from the sampled institutions were required to state whether they were aware of the HACCP principles. The results were as shown in Figure 2.

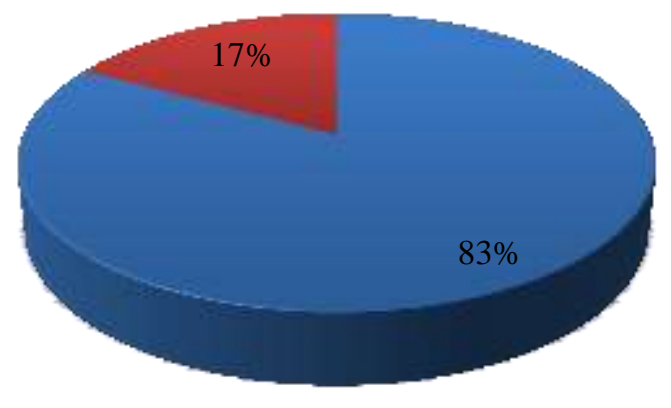

$\square$ Yes

$\square$ No

Figure 2:- Awareness of HACCP and the Pre-requisites 
The finding on figure 2 showed that a significant proportion of students $(83 \%)$ in the hospitality institutions were aware of HACCP and food safety codes of practice. This implied that food safety and hygiene practices were no longer a new concept in the training institutions. The finding on awareness was consistent with the report given by Minnesota Department of Health (2010). In that report, it was observed that there has been a significant improvement in the knowledge and awareness of food safety code of practice in the recent years in many countries.

Existence of a smaller percentage (17\%) of respondents who responded that they were not aware of HACCP implied that there was a major disparity among the graduates of various hospitality schools in Kenya. This disparity in the awareness of HACCP though small, posed a big challenge to institutions and industries hiring Food Managers and food handling personnel in Kenya who are trained from these institutions. Although this was considered important, an interesting observation by Roberts (2008) revealed that food service managers and employees who had received training on food safety knowledge did not translate the knowledge into practice. Despite this observation, Hertzman and Bannash (2007) advised that personnel who handled food must be knowledgeable and adhere to sanitation guide lines and practices. King (2013) also echoed the same sentiments that there was need for formal trainings targeted to the required level of knowledge.

A similar research was conducted to assess food hygiene awareness of professional food handling personnel from institutional catering companies in Portugal (Martins, Hogg and Otero, 2012). The results indicated that the level of formal education (56\%) significantly influenced the level of knowledge with a standard deviation of 3.22. Birchenough (2000) also observed that there were strong correlations between awareness and positive food handling practices. This result reinforced the importance of conducting a preliminary assessment of training needs and evaluating the effectiveness of the training as suggested by Rennie (1999). From the finding it was concluded that the student could know what to do but if emphasis was not enforced by their lecturer they would ignore the food safety measures. This could be one of the reasons why food safety was still a challenge in many countries including Kenya. A summary of the level of awareness of food safety hygiene code of practice between TVET and University hospitality schools is shown in Figure 3.

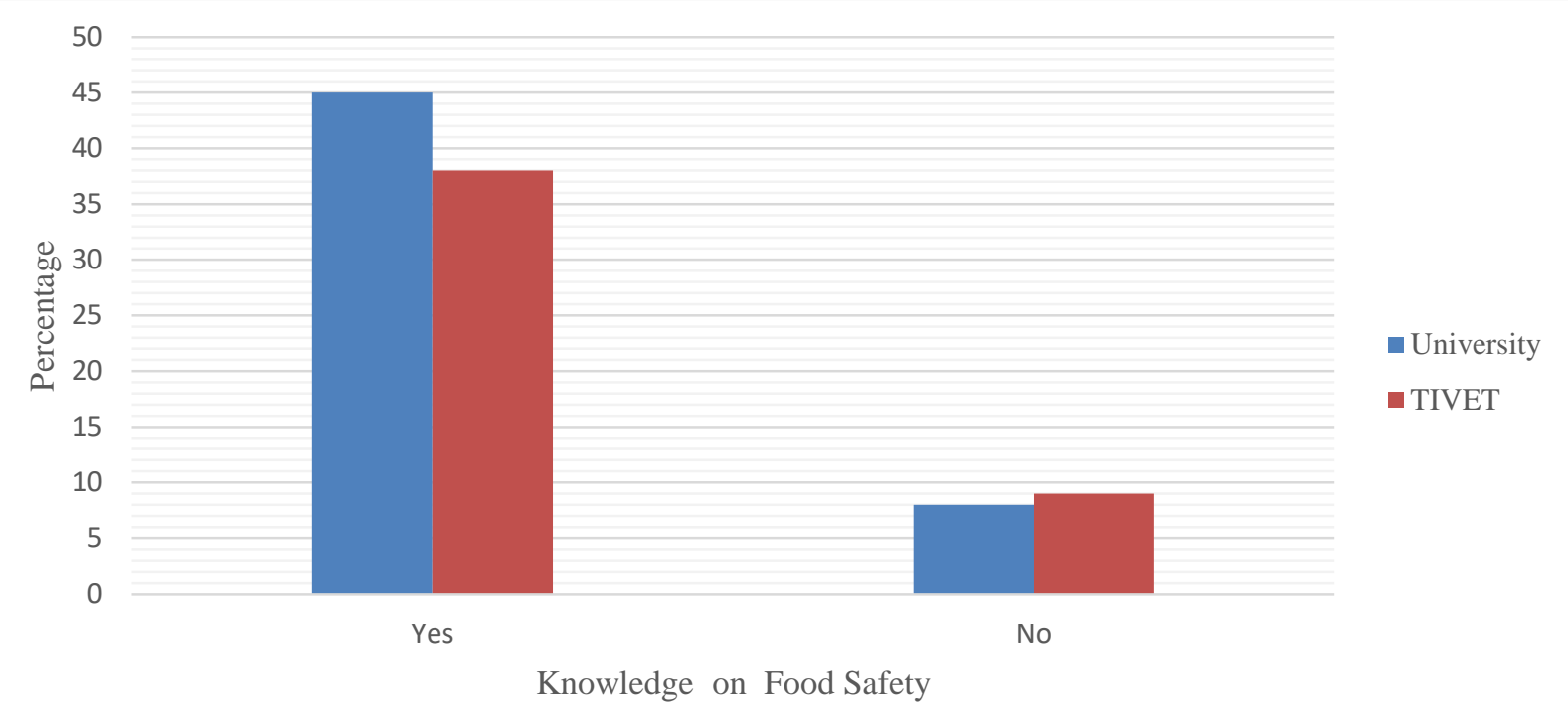

\section{Figure 3:- Awareness of Food Safety Hygiene Code of Practice (HACCP) between TVET and University Hospitality Schools}

From the summary in Figure 3, it was evident that respondents from Universities (45\%) were aware of food safety and hygienic practices compared to respondents from TVET colleges at (38\%). Conversely, only $8 \%$ of all respondents from Universities and 9\% of the respondents from TVET colleges were not aware of food safety and hygiene practices. 


\subsection{Testing Hypothesis}

Findings in Figure 3 suggested that there was disparity in the level of awareness of food safety and hygiene practices between Universities and TVET institutions. To assess whether the differences in the level of awareness of HACCP between the institutions was significant, hypothesis testing techniques were employed. The hypothesis was therefore formulated as

\section{$\mathrm{H}_{01}$ There is no significant difference in awareness food safety hygiene code of practice (HACCP) between TVET and university hospitality schools}

To test the hypothesis, chi square, was conducted to ascertain the significance in the relationship between level of awareness in TVET and University institutions. The tests were conducted at $95 \%$ confidence level. The level of significance ( $p$-value) was set as $\alpha=0.05$. The significance of the variations would therefore be confirmed if $\mathrm{p}$-value $<0.05$.

Table 1:- Cross Tabulation between Category of Institution and Awareness of HACCP

\begin{tabular}{|l|l|l|l|l|}
\hline \multicolumn{2}{|c|}{} & \multicolumn{4}{|l|}{ Awareness of HACCP } \\
\hline \multirow{3}{*}{ Category of Institution } & TVET & Yes & No & Total \\
\cline { 2 - 5 } & University & $224(79 \%)$ & $88(21 \%)$ & $422(100 \%)$ \\
\cline { 2 - 6 } & Total & $558(83 \%)$ & $25(10 \%)$ & $249(100 \%)$ \\
\hline$\chi^{2}=8.320, p$-value $=0.001$ & & & & \\
\hline
\end{tabular}

From the Table 1, 90\% of students from University hospitality schools indicated that they were aware of food safety measures and HACCP compared to $79 \%$ in TVET institutions. As previously mentioned, this variation in awareness posed a big challenge to institutions entrusted with the mandate of training on food safety and hygiene practices in Kenya.

\subsection{Chi-Square Test on Institution Category and Awareness of Food Safety Hygiene Code of Practice} In testing the independence of institution category on awareness, the test yielded a $p$-value $=0.001$, which was less than 0.05. Since the p-value was less than the level of significance, the null hypothesis of independence was rejected. This decision implied that there was a significant relationship between institution category and code of practice on awareness.

Based on the Chi-square test and previously presented tables and figures, the study deduced that even though a significant portion of students were aware of Food Safety Code of Practice control system, a good number still had inadequate information about Food Safety Code of Practice. King (2013) also highlighted this observation by indicating that there was need to appropriate food safety training, the education needed and the level of comprehension of the trainees. From the hypothesis tested, it was concluded that there was a close association between the institution category and awareness of Food Safety Code of Practice (HACCP). This relationship, however, significantly varied from one institution to another.

\section{Summary of The Findings of The Study}

The purpose of this study was to assess the level of awareness of Hazard Analysis and Critical Control Points (HACCP) principles in TIVET and University hospital schools in Kenya. The study found that 83\% of the respondents interviewed were aware of the HACCP principles while $17 \%$ were not aware. The study revealed that $(45 \%)$ respondents from Universities were aware of food safety and hygienic practices compared to respondents from TVET colleges at (38\%). In testing the independence of institution category on awareness, the test yielded a $p$-value $=0.001$, which was less than 0.05 . Since the $p$-value was less than the level of significance, the null hypothesis of independence was rejected. This decision implied that there was a significant relationship between institution category and code of practice on awareness.

\section{Conclusions}


The study concluded that even though the majority of the respondents indicated that they were aware of HACCP principles and food safety, they did not practice what they knew. The study also concluded that food service trainees had the theoretical knowledge but translating the same knowledge into practice was a big challenge. This confirmed the earlier findings from other researchers that the theoretical knowledge alone did not translate into safe food practice.

\section{Recommendations}

The study recommended there is need to create more awareness on HACCP principles and for food safety by holding workshops, seminars and sensitization programme to the stakeholders of hospitality industry.

\section{References}

[1] Abegaz, M. (2007). Trade capacity building in agro-industry products for the establishment and proof of compliance with international market requirements. UNIDO, Vienna 3, 6-9.

[2] Acheson, D. (2011). Slides on food safety and legislation. Food Journal 102(6), 145-156. In Food Safety Modernization Act.

[3] Adams, M. (2002). Food microbiology (2 ${ }^{\text {nd }}$ Ed.). Cambridge: Royal Society of Chemistry.

[4] Adams, M., \& Mortajemi, Y. (2003). African Cities (Abstract). Bulletin on Food Safety for Health Workers, Geneva, Switzerland. WHO, 21-22.

[5] Akonor, P. T., \& Akonor, M. A. (2013). Food Safety Knowledge: The case of Domestic Food Handlers in Ghana 3(3), 99-110.

[6] Anding, D. J. (2001). Self- reported changes in food safety behaviours among the food service employees: Impact of a retail food Safety education programme. Journal of Food Safety Science Education, 6, 72-76.

[7] Angelillo, N. M., Vigiani, L. Rizzo, A. B. (2000). Food handlers and food borne diseases. Knowledge attitude and reported behaviour in Italy. Journal of food pretection, 63 (3), 381 - 385.

[8] Bas M, Ersun AS, Kıvanç G (2006) Implementation of HACCP and prerequisite programs in food businesses in Turkey. Food Control 17: 118-126.

[9] Besselt, W. H., (Ed.) (2004). Clay's handbook of environmental Health. (19 ${ }^{\text {th }}$ Ed.) London: Spon Press.

[10] Blanch, S. (2003). Food Hygiene. London. Hodder and Stoughton

[11] CDC (2004). Emerging Infectious Diseases Journal 18(3).

[12] CDC (2005). Foodborne illnesses. International Food Safety Consultancy.

[13] CDC (2005). Foodborne illnesses. International Food Safety Consultancy.

[14] CDC (2010). Centers for disease control and prevention outbreak surveillance data. 2010 [cited 2012 Jun 22]. http://www.cdc.gov/outbreaknet/surveillance_data.html.

[15] Clayton, D. A., \& Griffith, C. J. (2004). Observation of food safety practices in catering using rotational analysis. British Food Journal 106(3), 211-227.

[16] Codex (2003). Hazard Analysis Critical Control Point (HACCP) and guidelines for its application "Codex Alimentarius, Food Hygiene Basic texts, joint FAO WHO Food Standards programme Codex Alimentarius Commission. Rome

[17] Egan, M., Raats, M., Grubb, S., Eves A., Lumbers, L., Dean, M., Adams, M. (2007). A Review of food safety and food hygiene training studies in the commercial sector.

[18] Ergonul, B. (2003). Application of HACCP system in Turkey. Int. J. of Food Safety, 3: 20-24.

[19] FAO/WHO (2005). Regional Conference of Food Safety for Africa. Harare, Zimbabwe 2005.

[20] Giampaoli J, Cluskey M, Sneed J (2002) Developing a practical audit tool for assessing employee food-handling practices. J Child Nutr Manag.

[21] Green, L. R. (2003). Behavioural sciences and food safety. Journal of environmental Health, 71(2) 47-49.

[22] House, A.M and Martel P. (2011). On Cooking: A Textbook of Culinary Fundaments. Upper Saddle River, NJ: Pearson Prentice Hall.

[23] Hwang, J.H., Almanza, B.A., \& Nelson, D.C. (2001). Factors influencing Indiana school foodservice directors/managers' plans to implement a Hazard Analysis Critical Control Point (HACCP) program. The Journal of Child Nutrition \& Management, 25, 24-29. 
[24] Jonathan N. (2005). Food Safety in the Biotech Era. UConn Libraries Published Works: University of Connecticut Libraries

[25] Jung H. (2005). Innovations in Food Packaging. San Diego: Academic Press.

[26] Lee, J. A., (2005). New Zealand approaches to HACCP systems. Food Control, 11(5), 373-376.

[27] Legnani, P. (2004). Hygiene control of mass catering establishment. Microbiological monitoring of food and equipment. Food Control,15, 205-211.

[28] Lewis, M. J. \& Neil J. H. (2005). Purchasing, selection and procurement for the hospitality industry. Hoboken, New Jersey: John Wiley and Sons.

[29] Mc Lauchlin, J., Grank, K.A., \& Little, C. L. (2006). Foodborne botulism in U. K. Journal of Public Health 28, 337-342.

[30] Mitchell, R. E., Fraser, A. M. \& Bearon, L. B. (2007). Preventing food-borne illness in food service establishment: Broadening the framework for intervention and research on safe food handling behaviours. International of Environmental Health Research, 17 (1), 9 - 24.

[31] Mortajemi , Y. and Kaferstein F. K. (1997). Global Estimation of foodborne diseases. World Health Statistics Quarterly, 50(1/2), 5-11.

[32] Mortlock, M. P., Peters, A. C., \& Griffith, C. (2009). A National Survey of Food Hygiene Training and qualification levels in the U. K. Food Industry. International Journal of Environmental Health 10, 111-123.

[33] Panisello, P. J., Quintic, P.C., and Knowles, M. J. (1999). Towards the implantation of HACCP: Results of a U.K. Regional survey. Food control 10(2), 87 - 98.

[34] Paster, T. (2007). The HACCP Food Safety Employee Manual. John Wiley \& Sons, Inc., Hoboken, New Jersey.

[35] Rangel J. M., Sparling, P. H., Crowe, C., Griffin, P. M., \& Swerdlow, D. (2005). Epidemiology of Escherichia Coli.

[36] Robbs, (2005). Incentive structure for food safety and quality assurance: an International Comparison. Food Control, 13, 77-81.

[37] Sneed, J., \& White, K.T. (2002). Continuing education needs of managers in school foodservice. School Food Service Research Review, 17, 50-61.

[38] Taylor, E. A., (2008). A new method of HACCP for the catering and food service industry. Food Control 19, 126-134.

[39] Todd, E.C.D and Farber, J.M. (2002). Safe Handling of Foods, Marcel Dekker, New York, NY.

[40] Vela, A. R., \& Fernandez, J. M. (2003). Barrier for the developing and implementation of HACCP plans: Results from a Spanish regional survey. Food Control, 14(5), 333-337.

[41] Walker, E., Pritchard, C., \& Forsythe, S. (2003). Food handler's hygiene knowledge in small food businesses. Food Control, 14(5), 339-343

[42] WHO (2003). Evaluation of programmes to ensure food safety, guiding principles. Geneva: Switzerland.

[43] WHO (2007). Food Safety and Food-borne Illness. Fact Sheet 237, www.who.int/mediacentre/factsheets/fs237/en/www.who.int/entity/foodsafety/publication/consumer. 